\section{Forced-Choice Test}

Philip Schatz

Department of Psychology, Saint Joseph's

University, Philadelphia, PA, USA

\section{Definition}

A forced-choice test is one that requires the testtaker to identify or recognize a previously presented stimulus by choosing between a finite number of alternatives, usually two. The forcedchoice format is useful when suboptimal effort is of concern to the examiner and is based on the premise that even impaired individuals will not perform below "chance level" (e.g., 50\% with two alternatives). Performance at, or below, chance raises suspicion of symptom exaggeration, suboptimal effort, or malingering. Researchers have shown that forced-choice recognition tests achieve a high "hit rate" in the detection of noncompliance.

\section{Cross-References}

$>$ Malingering

- Portland Digit Recognition Test

- Recognition Memory

- Test of Memory Malingering

- Word Memory Test

\section{References and Readings}

Frederick, R. I., \& Speed, F. M. (2007). On the interpretation of below-chance responding in forced-choice tests. Assessment, 14(1), 3-11. 